$c$-dimensions of carbon, however, must still be computed from equation 2 , since the $000 \mathrm{l}$ reflexions are not cross-grating spectra.

These results are so reasonable that there can be little doubt that they afford a direct verification of the validity of equations 1 and 3 . I have long felt that the existing values of the $a$-dimensions for 'amorphous' carbons calculated from Debye-Scherrer photographs have been much too small. Earlier results seem to indicate that the first stages in the grain-growth of carbon could be associated with rodlike crystallites, whereas plate-like crystallites seem much more reasonable on the basis of our existing

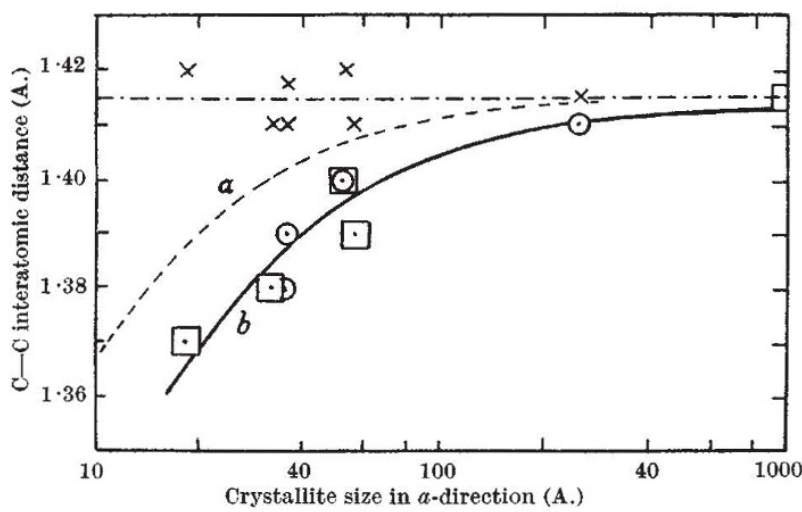

曰 Mean of Hofmann and Wilm's results ${ }^{4}$ on new basis. Curve $b$. $\odot$ Mean of Blayden, Riley and Taylor's results ${ }^{5}$ on new basis. curve $b$.

$\times \cdots \times \mathrm{C}-\mathrm{C}$ distances of curve $b$ with Warren correction.

.... Mean curve for $\mathrm{C}-\mathrm{C}$ interatomic distance on basis of original values given in published data ${ }^{4,5}$.

knowledge of the grain-growth of crystals. The new cross-lattice dimension equation is in conformity with these latter ideas.

Similar cross-lattice problems may also arise in the study of alloys, where phases precipitate out of solid solution in the form of fine lamellæ, or where two allotropic modifications of the same element, hexagonal close-packed and cubic face-centred cobalt, for example, form successive layers of submicroscopic thickness by gliding along planes perpendicular to a common trigonal axis.

Scott Motors (Saltaire), Ltd.,

A. TAYLOR. Shipley, Yorks.

${ }^{1}$ Warren, B. E., Phys. Rev., 59, 693 (1941).

${ }^{2}$ von Laue, M., Z. Krist., 64, 115 (1926); 82, 127 (1932).

'Scherrer, P., "Kolloidchemie", third edition, 387 (Zsigmondy, 1920). Jones, F. W., Proc. Roy. Soc., A, 166, 16 (1938). Patterson, A. L Phys. Rev., 58, 972, 978 (1939). Taylor, A., Phil., Mag., 31, 339 (1941).

'Hofmann, U., and Wilm, D., Z. Elektrochem., 42, 504 (1936),

${ }^{5}$ Blayden, H. E. Riley, H. L, and Taylor A., J. Chem. Soc., 67 (1939) . S., Riley, H. L., and Taylor, A., J. Chem. Soc., 67 Instr., 18, 91 (1941).

' Schoon, T., Angew. Chem., 51, 608 (1938).

\section{Buddleias on a Bombed Site}

THE appearance of considerable numbers of plants of Buddleia variabilis on a bombed site in Kensington, as recorded in NATURE ${ }^{1}$, is not an isolated case. During a recent study of the flora of the site of three bombed houses in Kew, numerous Buddleia plants were found. The houses were bombed in the autumn of 1940 and the sites cleared in the following spring. In addition to many weeds characteristic of waste ground there are at least sixty Buddleias. Some of these are 5-6 ft. in height and have bloomed freely ; others are smaller plants but many have also flowered. There are no Buddleias in the gardens of these three houses, and I have not identified the parent plant, but Buddleias are present in the neighbourhood though at some distance. Buddleia seeds are extremely small and have certainly reached the site by being wind-blown. The success of the plants is probably largely due to their long, sturdy tap-roots, which have been able to penetrate the hard downtrodden surface material and to reach the sandy sub. soil.

13 Burlington Avenue,

Kew Gardens. Sept. 18.

${ }^{1}$ NATURE, 150, 320 (1942).

\section{Mating Call-note of Moths}

A FEW days ago, a female ground lackey ( $\mathrm{Mala}^{2}$. cosoma castrensis) was disturbed in daylight from its shelter in canvas in a loggia. It alighted on a table and commenced to vibrate its wings in a very small radial are to attract the male. Bending low over the moth, I was astonished to hear a powerful, low-toned hum like that of a distant single-engined fighter. As the latter are not uncommon here, the observations were repeated to make sure the ear was not deceived.

Formerly, it has been suggested that the female emitted waves of a length too short to be perceived aurally. I had earlier discovered that this quivering of the wings could be induced by gently stroking the dorsal hairs of the Silver Y (Plusia Gamma), but on that occasion no aural observation was taken.

\section{Russell-Cotes Art Gallery and Museum,} N. L. Silvester.

East Cliff, Bournemouth. Sept. 12.

\section{Nova Cygni (1942)}

ON September 18 the Norman Lockyer Observatory, Sidmouth, was informed of the discovery by Zwicky of a nova in Cygnus at R. A. $20 \mathrm{~h}$. $56 \mathrm{~m}$. Dec. $+35 \cdot 7^{\circ}$, mag. 8. Cloudy sky prevented an observation before September 22. Since this date the region has been photographed seven times on four nights. Clouds prevented more work being done and bright moonlight restricted the exposure time. Only the night of October 1 was elear and steady, and a photovisual exposure of $2 \mathrm{~h}$. was obtained.

Photographic and photovisual magnitudes were determined with the help of about twenty standard stars (taken from the H.D. catalogue) and are listed in the following table :

$$
1942 \begin{array}{cccc}
\text { Date } & \text { Exp. } & m p & m p v \\
\text { Sept. } 22 & 7 \mathrm{~m} .30 \mathrm{~s} . & 10 \cdot 14( \pm 0 \cdot 18) & 10 \cdot 03( \pm 0 \cdot 17) \\
, " 23 & 20 \mathrm{~m} . & 12>N>11 \cdot 5 & 12>N>11 \cdot 5 \\
\not, 24 & 20 \mathrm{~m} . & >12 & >12 \\
\text { Oct. } 1 & \text { 2h. } & & 15 \cdot 5>N>14.5
\end{array}
$$

While the exposures of September 22. gave a well defined star image in $7.5 \mathrm{~min}$., the magnitude decrease was so rapid that no later exposure yielded a measurable image despite increased exposure time : on the plates of September 23 the star image could be easily recognized but not measured; on the plates of September 24 no star image appeared at all, the faintest star magnitude on the plate being about 12 